CHAPTER 126

MODEL STUDY OF TRANSFORMATION OF TSUNAMIS IN URADO BAY

\author{
ShIgehisa NAKAMURA \\ Research Assistant, \\ Disaster Prevention Research Institute, \\ Yuichi IWAGAKI \\ Professor, \\ Department of Civil Enguneering \\ and \\ Yoshzto TSUCHIYA \\ Professor, \\ Disaster Prevention Research Institute, \\ Kyoto Unlversity, Kyoto, Japan
}

\begin{abstract}
For the city and harbour of Kochl, Including Urado Bay, facing the Pacific Ocean, an experimental study has been carried out on the problem of protection from tsunami disasters, and future harbour planning; that is, dredging, reclamation and construction of breakwaters against tsunamis. A hydraulic model of horizontal scale $1 / 250$ and vertical $1 / 100$ was used according to Froud's similitude. The transformation of the design tsunam in the bay was studied to find the effect of the tounami breakwaters, dredging and reclamations by use of the model which was able to reproduce the Chilean Tsunami.
\end{abstract}

\title{
INTRODUCTION
}

The clty and harbour of Kochl, Including Urado Bay, located in Shikoku Island facing the Pacific Ocean as shown in Fig.I, have in the past 30 years been severely damaged by several tsunamis, for instance, the one due to the Nankal Earthquake in 1946 and the Chllean Tsunami in 1960. Tounamis are malnly caused by Japan's position in a sesmic active zone so that a historioal review wall show plenty of damage by the tsunamis and their causat Ive earthquakes.

The characteristics of tsunamis have been studied theoretzcally, experimentally, and through fleld observations; but they should be studied too from the view point of coastal disaster prevention. A countermeasure has been the construction of seawalls. Recently the development of industries and of the harbour in Urado Bay have been planned, so it is necessary to study the effects of the construction of breakwaters and of the dredging andland reclamation in the bay on the behaviour of tsunamis. It 
was decided that the best approach would be conducting hydral zc model studies.

This paper deals to study the transformations of tsunamzs in the bay before and after completion of this project.

\section{TSUNAMI GENERATOR}

For this study, a tsunami generator of the plunger type was constructed, driven by an oll-hydraulic servo system. The plunger was made of steel, $7 \mathrm{~m} \times 3 \mathrm{~m} \times 0.5 \mathrm{~m}$, located as shown in Fig.2. Power Is supplied by an oll-hydraulic controller, shown in Fig.3. Transmission of an input signal is performed by a servo system, schematically given in the block diagram of Fig.l, to drive the plunger. The input signal is given by the cam of acrylite. In order to produce not only simisozdal regular waves but arbitrary waves, cams of various forms were used. According to the radius of the cam, the servo system controls the displacement and phase of the plunger through which the amplitude of the model tsunami wave is produced. By controlling the angular velocity of the cam, the perlod of the generated wave will be given. The stroke of the plunger is continuously variable and Its maximum $18 \pm 100 \mathrm{~mm}$, and the period of the cam for a cycle is variable contimuously in the range of 3 to $30 \mathrm{~min}$.

\section{SIMILITUNE AND THE MODEL}

First of all, the area of the model should be determined with consideration of tsunamis around the bay mouth.

The tsunamis which attacked this bay were from off Nankaldo, Hyuganada, the Aleutzan Islands, the Chilean coast, and so on. These tsunamis propagated and attacked the bay after refraction, deflection and rectifyzng the wave rays to the contours. The propagation maps of the tsunamis show that the fronts of the tsunamis were almost parallel to the contours in the coastal area of 15 to $20 \mathrm{~m}$ deep, whlch was taken as a criterion to limit the model area. The tsunamis which entered the bay should mun up the rivers so that the phenomena caused by the tsunamis should be found in the estuarys. The other criterion to lamit the model is to find the limit of the tidal and the tsunami influences refering to the field data.

Second, the distortion of the model should be checked in relation to the characteristics of the tsunamis. When the model experiment is carried out by use of a distorted model which has different vertical and horizontal scales, the slope of the bottom is distorted so that the reflection and refraction of the tsunamis might be generally different compared to those in the nondistorted and distorted models. And graphical analysis to give a refraction diagram of the tsunami in the bay shows a little 
difference up to the distortion of 2.5 ( $1 / 50$ of horizontal and $1 / 100$ of vertical ) with consideration of recording and processing errors of the data. It was reported that the Hilo harbour tsunam model gave a distortion 3.0 ( $1 / 600$ of horizontal and $1 / 200$ of vertical ) without effect of distortion to refraction and reflection of the tsunamis (Palmer et al., 1965).

In the estuary, saline water contacts fresh ruver water to mix vertically or to stratıfy into a stable double layer by the effect of the density difference of the waters. The river discharges flowng into the bay were so small compared to the tidal flushing that there should be prevalled vertical mixing which suggests that the consideration of the density difference might give little errors in the model experiment.

The similutude for the model was derived by the equation of motion and contimuly. Froud's similitude was applied to the model experiment; the scale ratios of the prototype to the model are 250 for horizontal length, 100 for vertioal length, 10 for current velocity, 25 for time, $2.5 \times 10^{5}$ for river discharge, and 100 for kinetic energy, respectively.

Generally, the flow regume og the prototype are turbulent so that the friction coefficient may be taken as a certain constant value. And for the model the cofficlent is a function of a Reynolds number, therefore it is difficult to hold tre similatude mentzoner riove for a rhol, peraol of experament.

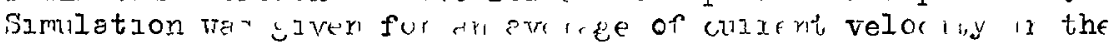
niouel rea.

Roughness of the bottom was simulated by use of Manning's formula for the current velocity as an average. The simulitude gives the scale ratıo 1.365 of Manning's roughness parameter. An artificial roughness was given in the model for simulation fulfilling the above condition. With the consideration of size distributions of sediments, the roughness parameter is 0.03 in the harbour part which is simulated as 0.022 in the model to give the roughness of 0.2 to $0.3 \mathrm{~cm}$ by brushing up the mortar surface. For the river part in the model, the roughness was given by fixing sands of 0.3 to $0.5 \mathrm{~cm}$ in size on the river bed mortar. Judging from the result of the experiment, the effect of the roughness was not distinctive compared to topographical influences.

The water level was recorder on the photographlc chart contimuously and simultaneously. For dynamical understanding, current velocity was obtalned from movies tracking floats of $1 \mathrm{~cm}$ in diameter in several areas in the model.

The model of Urado Bay is schematically shown in Fig.I for present topography and Is shown in Fig.4 as a burd's eye view. 


\section{REPRODUCTION OF CHILEAN TSUNAMI}

There are many records of damage caused by tsunam 1 inundation, there is a few records of tsunamis for Urado Bay. One of the representatiove tsunamis in Urado Bay was the Chilean tsunami of 1960 , which was recorded at three stations in the bay: Katsurahama(St.1), Urado(st.3), and Wakamatsu-cho(St.2l). The locations are shown in Fis.1. Trials were oarried out to reproduce this tsunami in the model basin. Tsunami records for the first four hours were reproduced us ing a cam as input under the dynamical consideration and repeating correction of the cam until the tsunami records of the prototype coincide with the wave records in the model experiments. One of the records is shown in Fig.5, in which the scales of elevation and time are in prototype according to the simlitude. From Fig.5 It is found that the wave forms in the model colncide well with each other in amplitude and phase as a whole. Especially, the wave form at St.l Is well reproduced. The detalls do not perfectly colnolde at $5 t .3$ and $S t .21$. At St.3, the experimental result shifts about $20 \mathrm{~cm}$ high compared to the prototype records. The distorted model might give the shift of the water level. At St.2I, the wave helght in the experiment is up to twlce as large as the tsunam records in the mareograms, which might be caused by the local topography around St.21. The river elevation increases from the end of the navigation cource to the Kagami river so that the water passing St.2l is affected by local topographical effects and shoaling effect. These detalled discrepancies between the prototype and the experiment should be studied for more accurate reproduction of the tsunami in the model experiment.

\section{DESIGN TSUNAMI AND ITS TRANSFORMATION}

Inundation from tsunamis in Kochi Harbour was studied by numerical computation ( Hamada et al., 1961). Scouring problems near the tsunami breakwaters at the entrance of KochI Harbour were studied experimentally by shibayama et al. ( 1964 ). The behaviour of tsunamis at the junctions of rivers were studied mumerically by Horıguch ( 1965). These computationg and experiments were carried out by use of a design ysunami determined by the records of the tsunami of the Nankaido Earthquake and of the ChIlean tsunam.. Hamada ( 1961 ) gave the design tsunaml at St. I such as the crest helght $1 \mathrm{~s} 2.4 \mathrm{~m}$ above and the trough $1.5 \mathrm{~m}$ below the mean high water level with the period of 30 min for the numerical computation.

Spectral analysis of the Chilean tsunami gave the significant period of 30 to $35 \mathrm{~min}$. For the Hyuganada Farthquake tsunami in 1968, the significant period was about $25 \mathrm{~min}$. 
These results suggest that the sultable period of the design tsunami is probably to be $30 \mathrm{mln}$ (Iwagakı et al., 1970). In this experiment the same conditions were given for the design tsunami. The inltial water level before the tsunami inundation was taken to be the mean high water level ( $1.1 .+1.89 \mathrm{~m})$.

The design tsunami that entered the bay propagates through the bay mouth; that is, the waves are transformed and their phases are delayed with the progress including the effects of the boundary and topography of the bay. There should be many factors affecting the transformation of the design tsunami, such as: phase velocity as a function of water depth, refraction caused by the bottom slope, deflection around a sharp edge, reflection at the coast and shoaling in the river mouth. The resultant effect of these factors gives the wave transformation. When the design tsunami at the entrance of the bay is given, the transformation of the wave in the model is obtalned through the experiment as shown in Fig. 6 in model scale. In Fig.6, wave height and time are shown in the model scale. The wave profiles are arranged ordinally for the stations, the locations of whlch are lllustrated by numbers in clrcles in this figure.

The wave profile at St.l is a simasoldal which is found the lowest part of Fig.6. The wave is transformed and decreases its helght at the narrow, the fact of which is found by comparison of the wave form at St.1, St.2 and St.5. There should be energy dissipation of the wave at the narrow caused by the confused configulation of the coast lines and to the curved water way. At the inlets, resonance occured by produce higher harmonics of the incidental tsunami. For example, the wave form at 10 suggests that the third harmonics of the tsunam is amplified in the small rectangular resonator in which the location of St.10 is included.

In the river part, the wave height increases with inundation of the tsunami as found the wave forms of St.22, 23 and 25 in Fig.6. In the Kuma river, the wave helght increases from St.23 to St.25. The wave form is transformed to be assymmetry; that 1s, the steep proflle before the crest and the gentle slope after the crest of the wave. These transformed wave profiles differ from the incldental sinusoldal wave at the entrance of the bay.

\section{CREST HEIGHT CHANGE AND TSUNAMI BREAKWATERS}

The crest height distributions of the design tounami were considered for the model of the present topography, the model without the tsunami breakwater for after dredging and reclamations, and the model with the tsunaml breakwaters for after dredging and reclamations. The distributions were obtalned as 
two dimentional or areal distrlbutzons whlch will give understanding about the complexity of the wave characteristics in the bay. In this paper, the distributions are shown only along the navigation course from the entrance to the head of the bay and along the Kagami River and Kokubu River or Kuma River, as shown in Fig.7. In Fig.7, the distances of the stations from the bay mouth are shown in reduced prototype scale in $\mathrm{Km}$ and the crest height of the tsunami in meter with reference to the elevation of the mean high water level. The locations of the stations in Fig.7 are shown by the numbers in circles. The dots, the circles and the semi-circles show respectively the case for the present topography, the case for after dredging and reclamations, and the case with the tsunami breakwaters for after dredgins and reclamations. The model for the conditions after dredging and reclamations is shown in Fig.8. Tsunami breokwaters are under planning for construction at the narrow point of the entrance of the bay, as shown in Fig. 8 .

The crest helght distributions are shown in Fig. 8 al ong the navigation course and the Kagami River. Comparing to the distribution for the present topography, the distribution for after dredging and reclamations suggests that the tsunami propagates with a little decrease of wave height because of water depth increase. But it is not clear why the crest helght at St, 2 beoame anomalously high after dredging. The effect of the reclamations is not so remarcable for the crest helght distribution. When the tsunami breakwaters are constructed for the harbour after dredging and reclamations, it is found a remarkable effect of the tsunaml-break-waters to diminish the wave helght in the bay and to protect the harbour from tsunami inundations around the bay mouth and in the bay. For the crest helght distributions, the effect of the tsunami breakwaters is not remarcable at the end of the navigation course. In the Kagaml River, there should be found a topographical effect for the tsunami inundations.

About the Kuma River or Kokubu River, the crest helght distributions are shown in the up-right part of $F_{18.7}$ to compare those to the main profiles of the crest helght in the same scale. There are found a little effect of the tsunami breakwater, dredging and reclamations in the profiles of the crest height distributions of the design tsunami.

\section{CONCLUSION}

From the results of the model experiment on tsunamis in Urado Bay, the authors obtalned the following conclusions.

1) By use of the tsunami generator with consideration of Froude's simllitude, the Chilean tsunami was reproduced in the model experimant. This result shows the possibllity of studying future problems in the bay. 
2) Transformation of the design tsunami and crest height distribution of the tsunami were studied to find the negative effect of dredging of the navigation course and to find the active effect of tsunami breakwaters for protection of the harbour from tsunami imundation. Reclamations gave a little influence on the crest height distribution and on the wave height of the tsunami.

Kochl was attacked directly by the typhoon 7010 on 21 , August, 1970 so that they suffered from heavy damages by the storm surge accompanied with the typhoon. Thls fact suggests that It should be promoted not only to study on tsunam but to investigate on storm surges in Urado Bay. Future plan of the harbour should be refered on the studies mentioned above to protect from coastal disasters.

\section{ACKNOWLPDGEMMENT}

The authors wish to express their thanks for the help given by the Manlstry of Transport and Kochl Prefecture.

\section{REF'ERENCES}

Hamada,T., Horıguchı,T., Kato,H. and Kaneko, 1". (1961). Calculation of tsunami inundation in a channel - - a case of Kochl Harbour ---, Proc. 8th Conf. Coastal Eng. In Japan, pp.30 - 35 ( In Japanese ).

Hor 1 guchı, T. and Ko, R。 (1965). Calculation of tsunamı Imundation in bay and river junctions, Proc. 12th Conf. Coastal Fing. In Japan, pp.14 - 18 ( In Japanese).

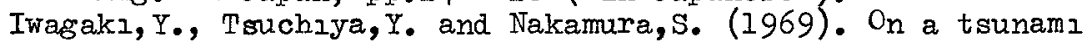
generator, Proc. 16th Conf. Coastal Eng. in Japan, pp.321 - 326 ( In Japanese).

Iwagakı, Y., Tsuchıya, Y. and Nakamura, S. (1970). Tsunamı model experiment of Kochl Harbour, Ann. Dis. Prev. Res. Inst. Kyoto University, No. 13 B, pp.47I - 488 (in Japanese).

Palmer,R.Q., Malvihlli,M.E. and Funasakı,G.T. (1965). H1lo Harbour tsunami model - - reflected waves superimposed, Castal Eng., Santa Barbara, Sp. Conf., ASCE, pp.21 - 31.

Shlbayama,H. Kimura,H. and Takemura,K. (1964). Model exper1ment on tsunami breakwater of Kochl Harbour, Rep. Port and Harbour Res. Inst., MInistry of Transport, Vol.3, No.2, pp.14 - I8 ( In Japanese). 


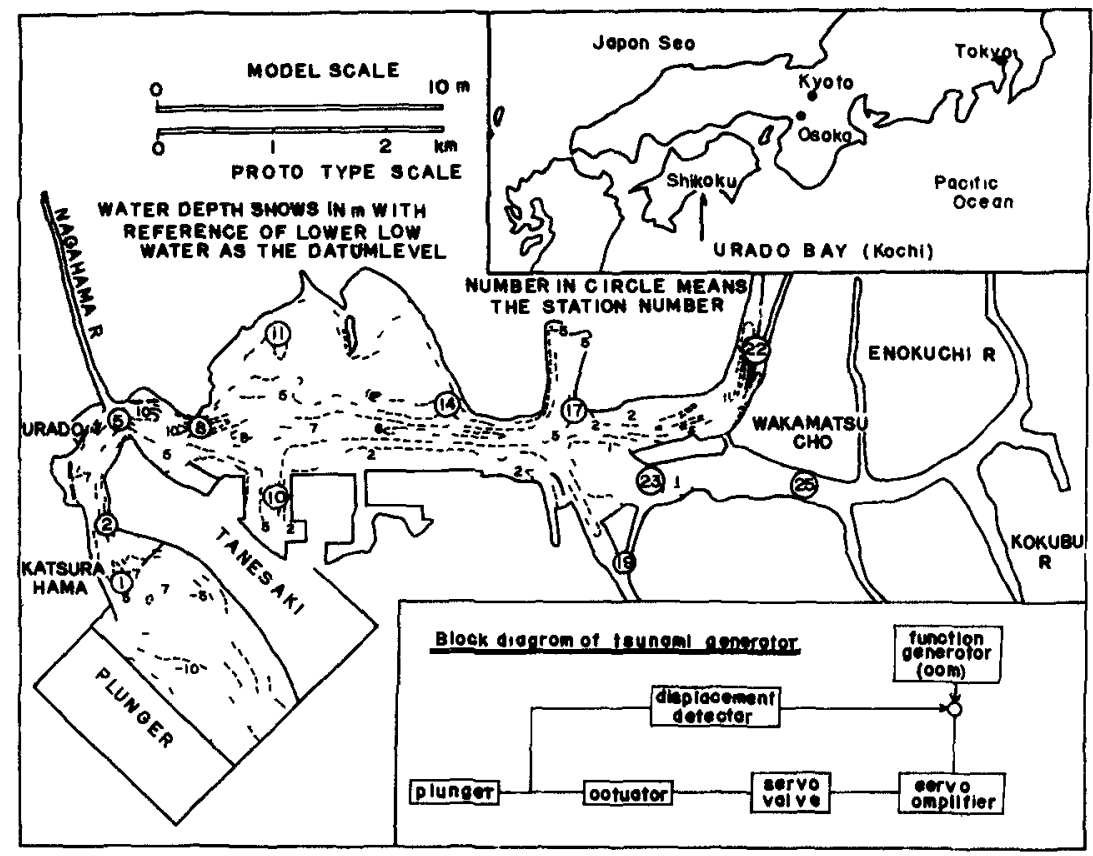

FIg.1 SCHEMATIC PLANE OF THE TSUNAMI MODEL OF URADO BAY ( Including locations of stations where water levels were recorded in the tsunaml model, and tide gauges are located at St.2, St.3, St.7, St.17 and St.21 in the prototype of the harbour) UP-RIGET: IOCATION OF URADO BAY DOWN-RIGET: BLOCK DIAGRAM OF THE SERVO SYSTEM 


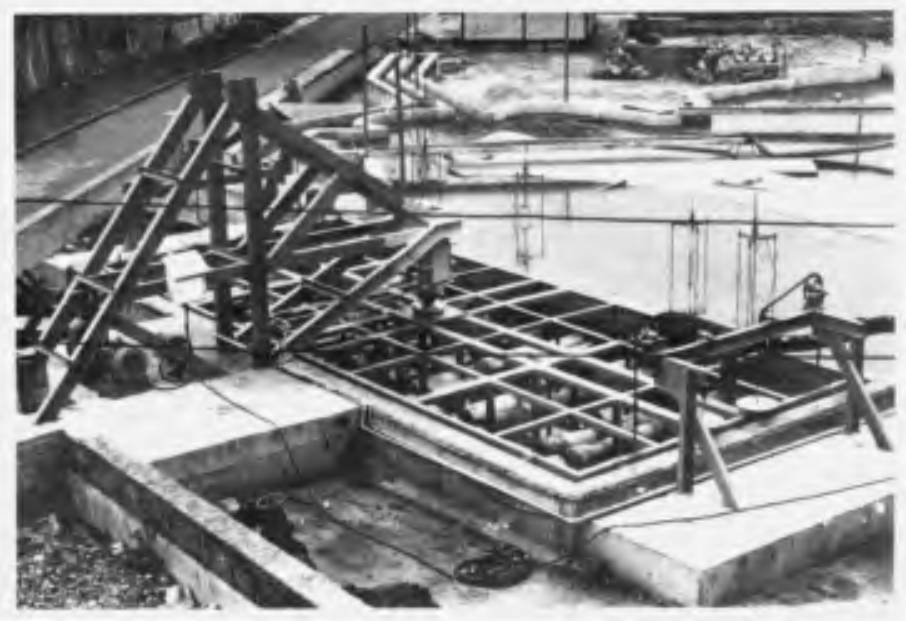

Pig. 2 PLUNGER OF THE TSUNAMI GENERATOR

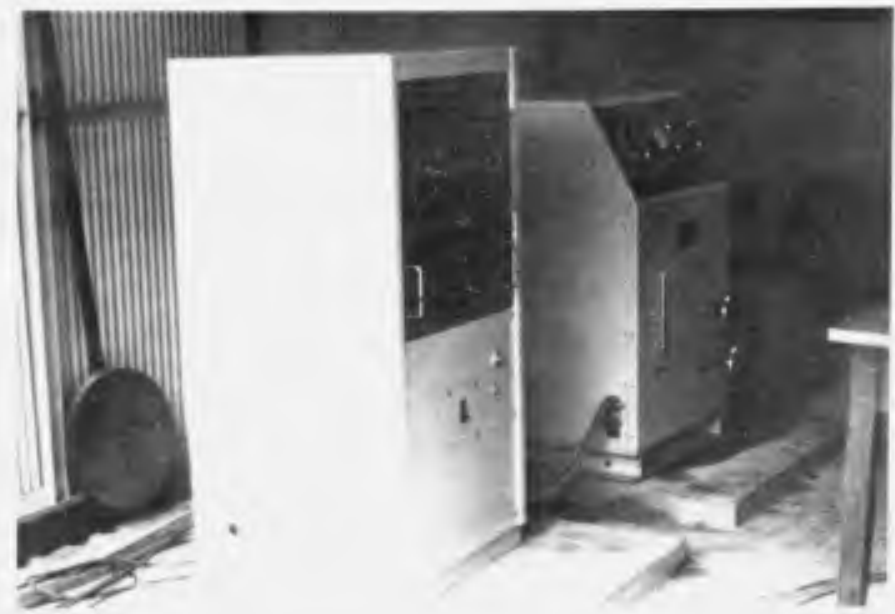

Fig. 3 OIL-HYDRAULIC CONTROLLER OF THE TSUNAMI GENERATOR 


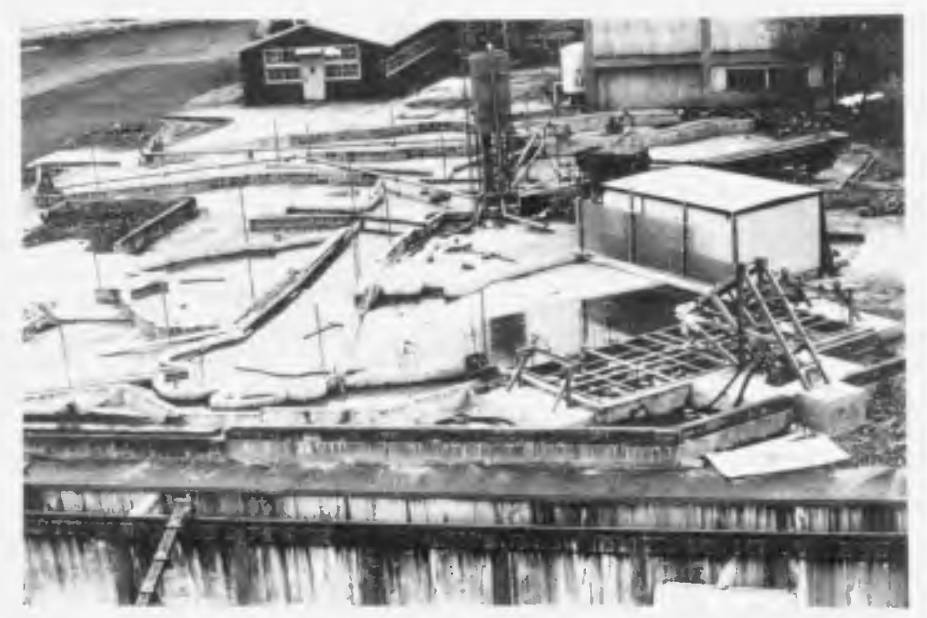

Fig.4 BIRD'S EYE VIEW OF THE TSUNAMI MODEL ( The plunger shown in Fig. 2 is at the end of the model. The controller is in the white cottage. The head tank at the center of this photograph supplys river discharges in the model.) 


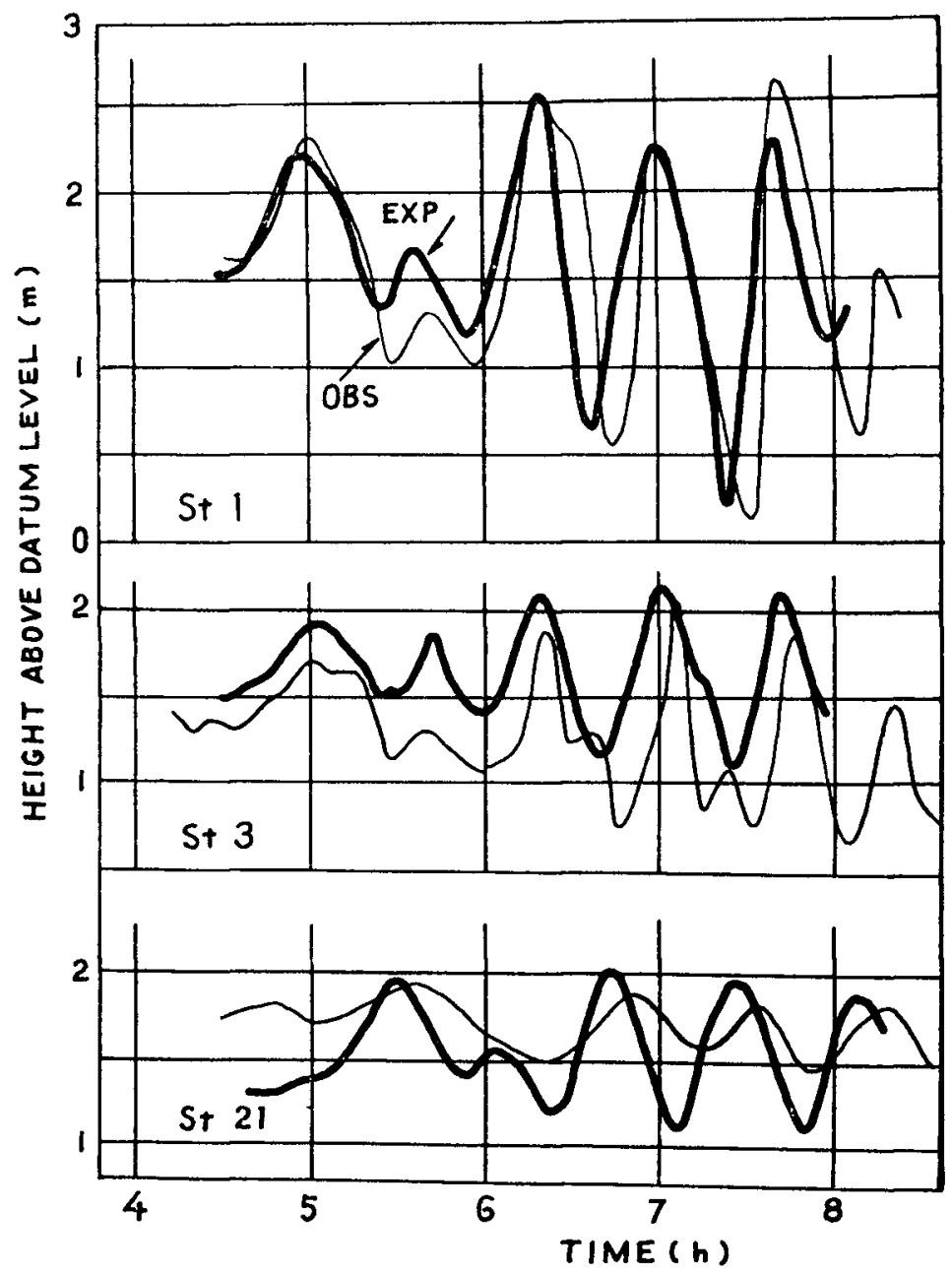

FIg. 5 RFPRODUCTION OF THE CHILEAN TSUNAMI IN URADO BAY 


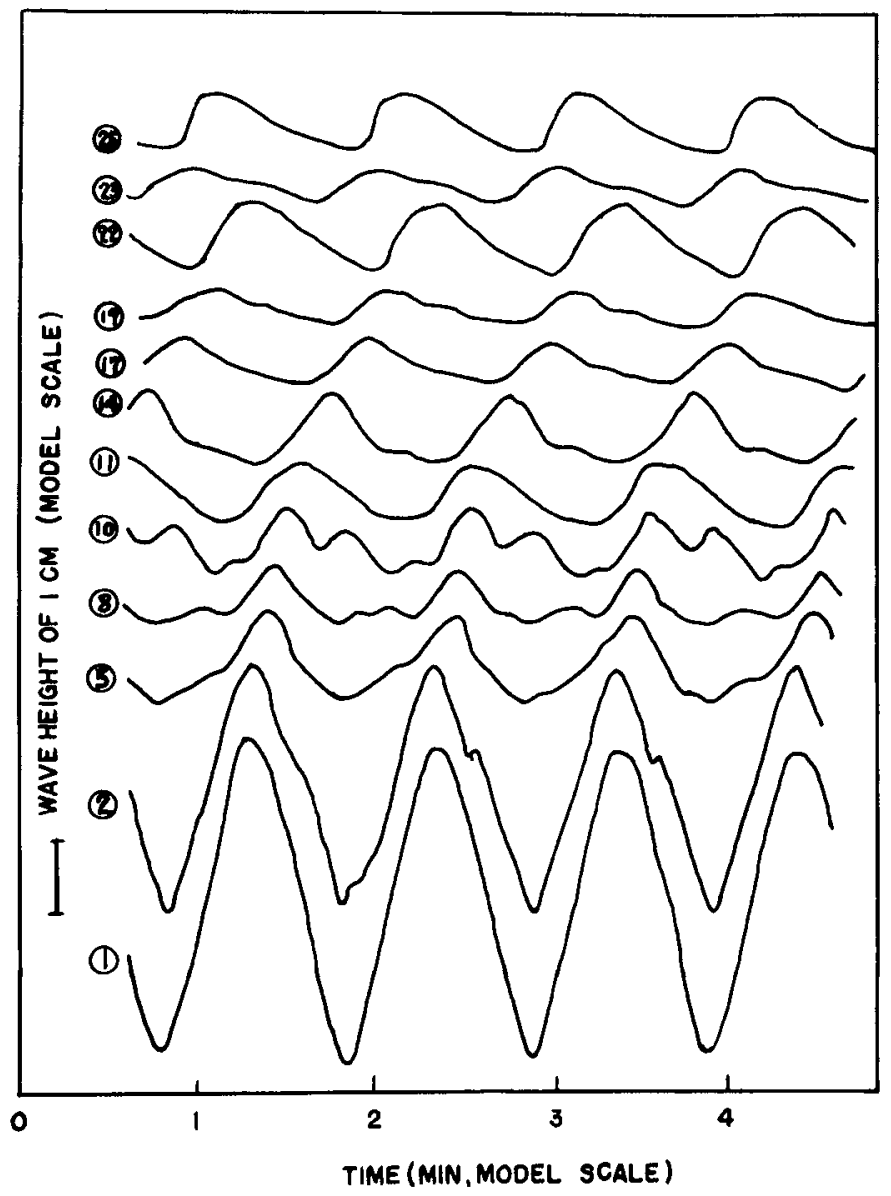

F1g. 6 TRANSFORMATION OF A DESIGN TSUNAMI 


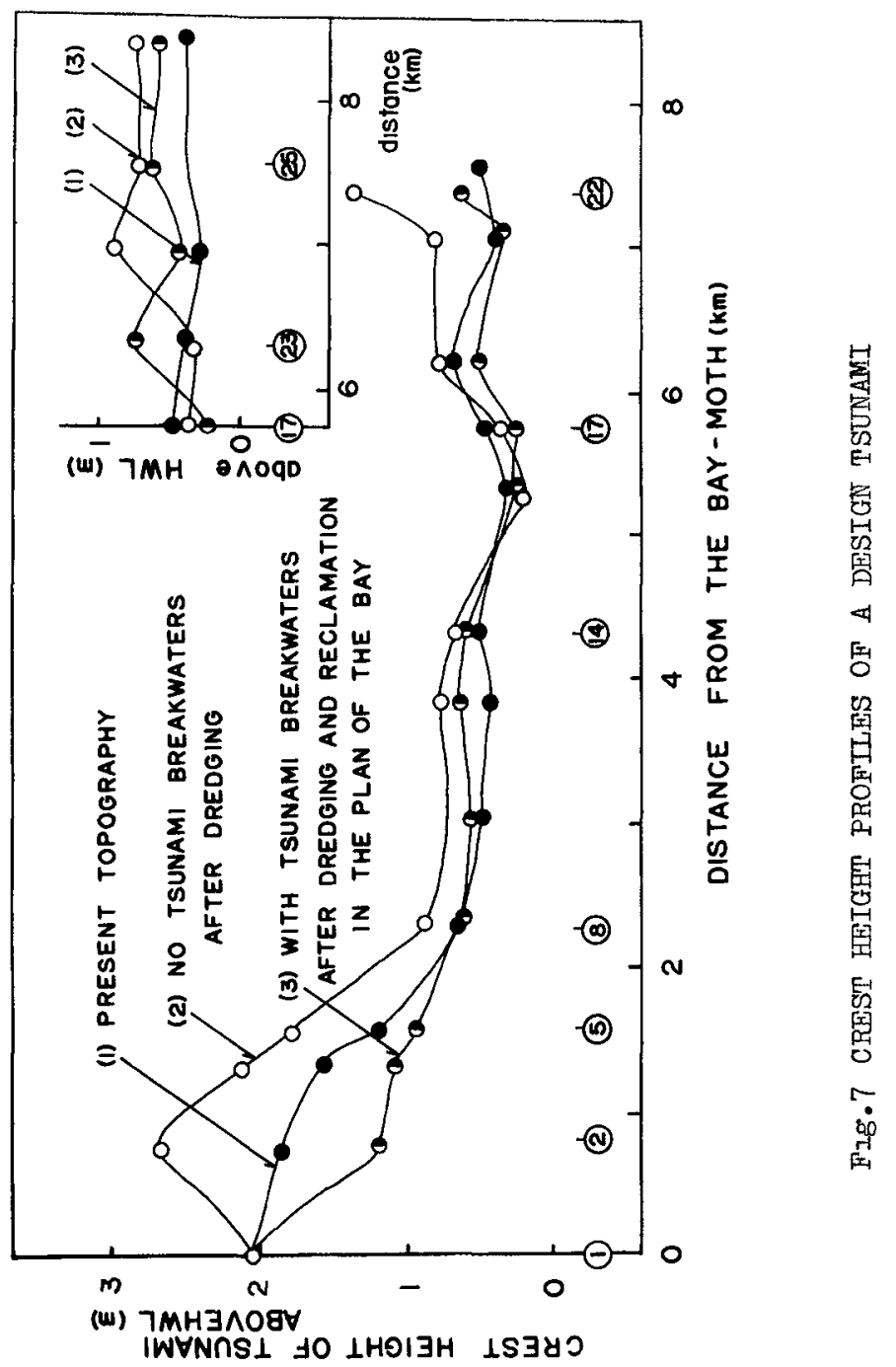




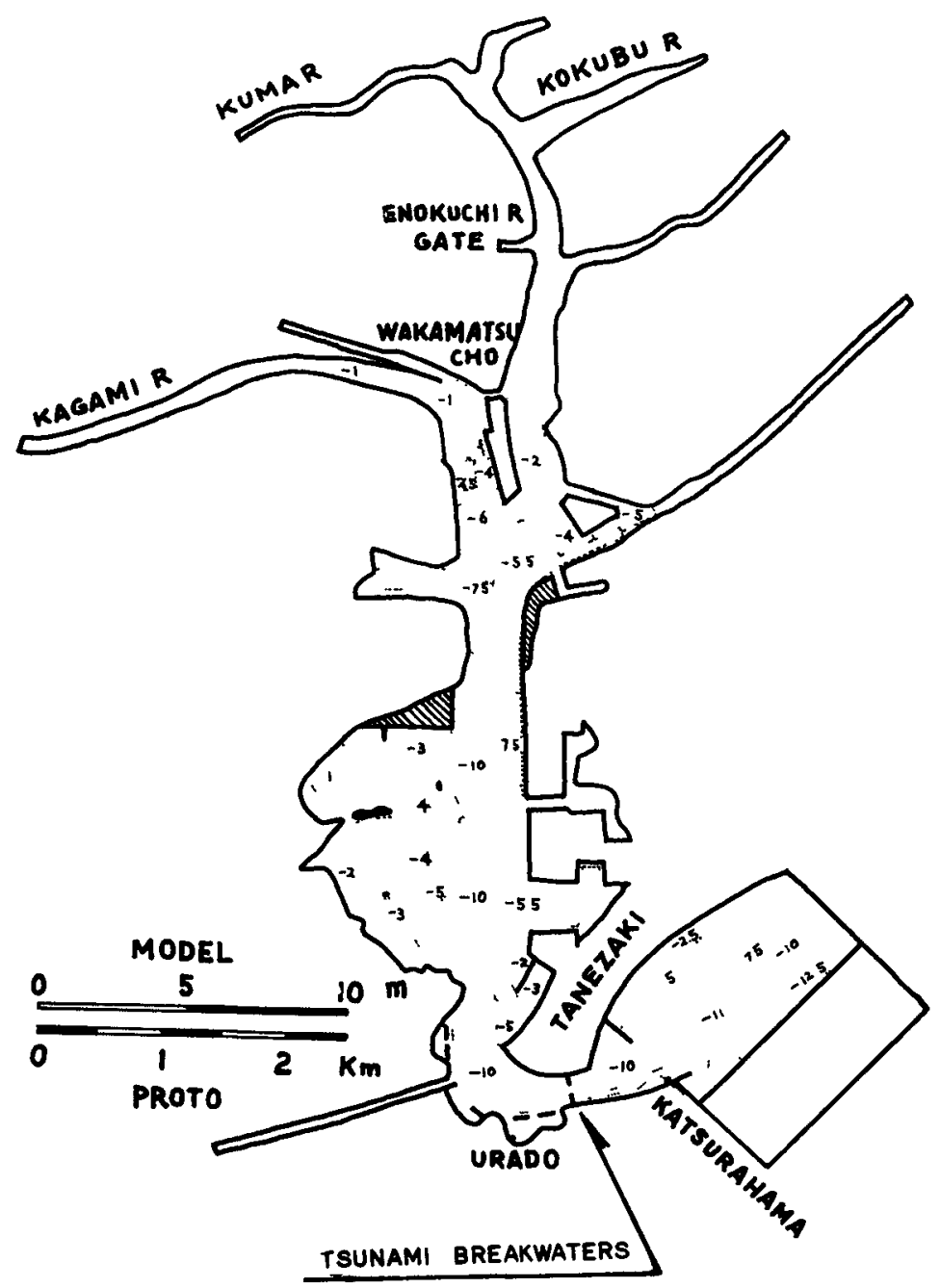

FIg.8 TSUNAMI MODEL AFTER DREDGING AND RECLAMATIONS ( The location of the tsunami breakwaters 18 indicated by an axrow.) 